\title{
Intertrial interval in the maintenance of discrete-trial avoidance'
}

R. G. Weisman, 2 D. J. Zerbolio and M. R. Denny MICHIGAN STATE UNIVERSITY

\begin{abstract}
Abstraet
The rate of acquisition for a shuttle box response has previously been shown to be positively related to the length of the intertrial interval to $5 \mathrm{~min}$. This study shows that the post-acquisition maintenance of avoidance is unaffected by the intertrial interval length from 15 sec. to $300 \mathrm{sec}$.
\end{abstract}

\section{Problem}

Brush (1962) found that increases in the length of the intertrial interval (ITI) up to $5 \mathrm{~min}$. facilitated acquisition of a discrete-trial shuttle avoidance response. The present study is also a parametric investigation of ITI in a shuttle box. We have chosen to focus on the maintenance of avoidance rather than its acquisition. We were interested in the steady state situation because, unlike free-operant avoidance (Sidman, 1955), discrete-trial avoidance has only occasionally been studied under "chronic" conditions (Anderson \& Nakamura, 1964; Badia \& Levine, 1964).

\section{Method}

The Ss were four adult male Sprague-Dawley rats from the colony maintained by the Psychology Department. An automated shuttle box (4 in x 14 in $\times 36$ in long) with stainless steel grids was used. Both warning signal (a transistorized buzzer) and $1.1 \mathrm{ma}$. shock from a Grason-Stadler shocker were response terminated. Unless an avoidance response occurred, shock onset was 5 sec. after the onset of the warning signal.

Each $\mathrm{S}$ had 10 sessions (40 trials each) with a variable ITI with a mean of $120 \mathrm{sec}$. to stablize the avoidance response. Then, for Ss D-1 and D-2 blocks of from 6-11 daily sessions (40 trials each) with a 210, 30,300 , or $15 \mathrm{sec}$. fixed ITI were alternated with the "baseline" 120 sec. variable ITI. For D-3 and D-4 the procedure was the same except that Ss were exposed to the ITI's in a different sequence: $30,210,15$, and $300 \mathrm{sec}$.

\section{Results and Diseussion}

Shuttles were scored as avoidance responses if they occurred during the first 5 sec. of the warning signal, escape responses if they occurred after shock onset, and intertrial responses if they occurred between signal presentations.

Percent avoidance responses and rate of intertrial responses for the final two days at each ITI are shown in Fig. 1. Since the variable $120 \mathrm{sec}$. ITI point was redetermined several times in the course of the experiment the median is given. Under the present steady state conditions ITI had no reproducible effect on avoidance responding, although one $S(D-4)$ did show
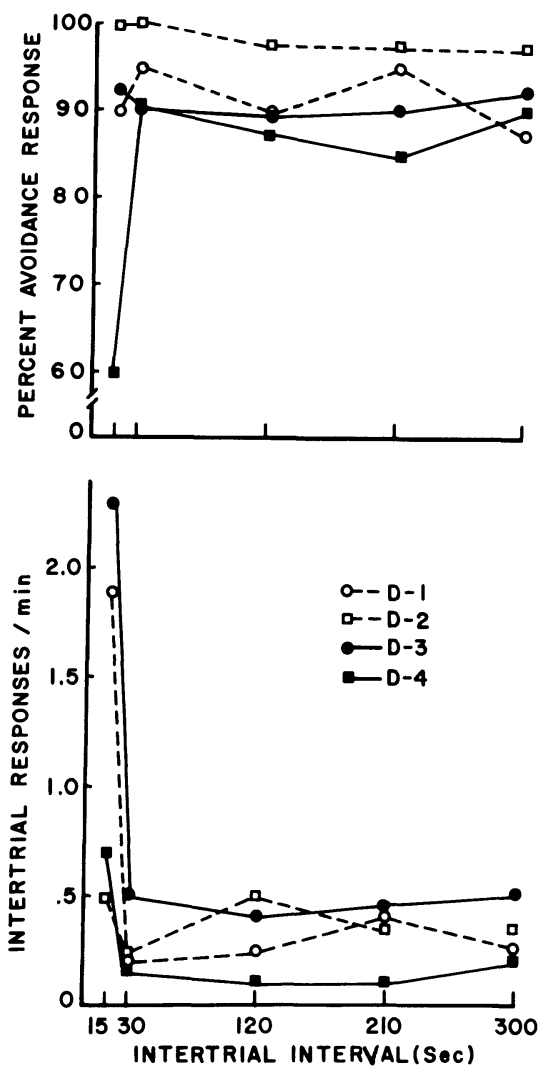

Fig. 1. Percent avoidance response and rate of intertrial response as a function of ITI length.

loss at the shortest interval. But the rate of intertrial responding showed a reliable increase at the shortest ITI (15 sec.). At other points the rate of intertrial responding was uniformly low. It is unlikely that this increase is due to an interaction with session length since increasing the session length to 60 trials at the 15 sec. ITI for a few sessions after the experiment proper did not result in a decrease in intertrial responding.

Perhaps the increase in intertrial responding with the $15 \mathrm{sec}$. ITI is related to Pearls' (1963) finding that short ITI's facilitate acquisition of discrete-trial lever press avoidance or to the parameters of Sidman avoidance.

Also of some interest was the failure to find the decrement with continued training observed for the wheel-turn response (Anderson \& Nakamura, 1964) but not for the shuttle response (Badia \& Levine, 1964). 
References

ANDERSON, N. H., \& NAKAMURA, C. Y. Avoidance decrement in avoidance conditioning. J. comp. physiol. Psychol., 1964, 57, 196-204.

BADIA, P., \& LEVINE, S. Stable long term avoidance responding and fixed ratio avoidance training. Psychon. Sci., 1964, 1, 91-92.

BRUSH, F. R. The effects of intertrial interval on avoidance learning in the rat. J. comp. physiol. Psychol., 1962, 55, 888-892.

PEARL, J. Intertrial interval and acquisition of a lever press avoidance response. J. comp. physiol. Psychol ., 1963, 56, 710-712.

SIDMAN, M. Some properties of the warning signal in avoidance behavior. J. comp physiol. Psychol., 1955, 48, 444-450.

\section{Notes}

1. Research supported by N.S.F. Grant GB-238 to M.R.D.

2. Now at Psychology Department, Queen's University, Kingston, Ontario, Canada.

\section{Editorial Note}

'In the next few weeks, readers will see an increasing "segregation" of articles in alternating issues of the journal. By April, the first issue each month will contain articles in Animal Behavior and Psychophysiology, while the second issue will consist of articles in Human Experimental Psychology.

The segregation will be gradual partly because there was no need to do it in a hurry and partly because many articles had already been scheduled when the decision to do it was made. The decision hinged on the increasing size of the journal and the need to devise a plan for the future that would be economical both for the subscribers and for the publishing of the journal.

The plan is to begin, in 1966 , to publish two volumes each year but to section the journal so that individual subscribers may, if they wish, subscribe to only half the issues. It happens that the division between articles in the animal and physiological areas and those in the human experimental areas is almost precisely $50 \%$. And although such a division may not suit everybody, it is a conventional one, corresponding roughly to the respective subject matters of the Journal of Comparative and Physiological Psychology and the Journal of Experimental Psychology, and it is a more practicable plan than any other.

We are beginning the sectioning feature of the plan this year so that the Editor can see what problems there are, if any, in carrying it out and so that readers can become accustomed to it and be ready to make their decisions when later they are called upon to choose between subscribing to one section or subscribing to the entire two annual volumes. 